\title{
Investigating of fear of COVID-19 after pregnancy and association with breastfeeding
}

\author{
Asiye Uzun ${ }^{1 *}$, Güzin Zeren Öztürk ${ }^{2}$, Zeliha Bozkurt ${ }^{2}$, Mehmet Çavuşoğlu ${ }^{2}$
}

\begin{abstract}
Background: COVID-19 pandemic has certainly become the most important global problem. Deficient information may increase the fear of COVID-19, affect pregnant women's psychology, and even affect breastfeeding during the postpartum period. This study aimed to assess the fear of the COVID-19 pandemic after pregnancy and its association with breastfeeding.

Methods: A cross-sectional study designed to survey all pregnant women who gave birth at $\geq 36$ weeks between March 10 and June 10, 2020, at the Private Nisa Hospital, Istanbul, Turkey. Participants respond to questions related to sociodemographic, genealogical, pregnancy, birth information, postpartum baby care, and breastfeeding status, in addition to the 7-item Fear of COVID-19 Scale (fcv-19s) via phone. Descriptive, bivariate, and linear regression analysis was performed to predict fcv-19s. SPSS version 22.0 was used to analyze the data.
\end{abstract}

Results: A total of 906 (response rate $78.8 \%$ ) respondents with a mean age of 29.59 ( \pm 4.74 years) were included in the study. Most of them were highly educated $(75.2 \%)$, housewives $(86.1 \%)$, and living in nuclear families $(96.1 \%)$. The majority of women (92.9\%) gave birth at 38 weeks via cesarean section (71.7\%) and breastfeeding (94.2\%). Although the mean score of fcv-19s was high in non-breastfeeding mothers, no significant correlation was seen in bivariate analysis. In the linear regression analysis, the highly educated, good income status, having at least once follow-up a month, having a history of psychiatric disease, cesarean section delivery, competence in baby care, breastfeeding, and milk adequacy significantly predicted the (fcv-19s) $(R=0.67, R 2=0.46, F=42.10, p<0.001)$.

Conclusion: During pandemics, including COVID-19, the psychological state of society is negatively affected, and therefore special attention must be given to the most affected groups, especially pregnant and postpartum women.

Keywords: SARS-CoV-2, Pandemics, Breastfeeding, Pregnancy, Fear of COVID-19, Istanbul, Turkey

\section{Background}

After its appearance in China, the COVID-19 pandemic soon affected the whole world [1]. The first case of COVID-19 in Turkey was detected on 11th March 2020 [2]. As of June 26, 2020, the total number of cases in Turkey was 194,511, while 167,198 patients have been treated, and $2.6 \%$ of the cases have died [3]. A global health and economic crisis, the COVID-19 pandemic has affected various aspects of life. The world was not ready to face such a crisis [4]. Factors such as worldwide mortality rates or constant exposure to pandemic-related news and social isolation cause individuals to live with fear and anxiety [5]. Especially for pregnant women who are in a psychologically sensitive period. As with many infections, pregnant women are in the risk group for COVID-19. A study showed that pregnant or postpartum women of the same age might have more intensive care requirements than nonpregnant

*Correspondence: asiye.uzun@nisahastanesi.com

${ }^{1}$ Department of Obstetrics and Gynecology, Medipol Teaching and Research Hospital, Istanbul, Turkey

Full list of author information is available at the end of the article women [6,7]. Although no data exist on the transplacental transmission of COVID-19 in infantile terms, the viruses were not detected in the amniotic fluid, umbilical cord blood, or placental tissue [8,9], several cases of infected newborns have been reported in a recent study [10]. Nevertheless, it remains unclear if these newborns were infected before, during, or after birth and in what ways they were infected [10]. Furthermore, there is no data on whether the infants can get infected through breast milk after childbirth or not [11]. The World Health Organization (WHO) considered it safe to breastfeed during the COVID-19 pandemic [12]. Additionally, limited information, lack of treatment and vaccines, and changing the daily number of cases may increase the prevalence of mental disorders, including the fear of COVID-19 among pregnant women [13]. The impact of mothers' psychological problems can extend to disrupt the relationship between the mothers and their babies and even affect breastfeeding [14]. Therefore, the present study is intended to investigate the fear of COVID-19 and the related factors among a sample of Turkish pregnant women in Istanbul City. 


\section{Methods}

Study population and sample

A cross-sectional phone-based study designed to survey pregnant women attending the private "Nisa Hospital" in Istanbul city, Turkey. The study was conducted during the periods between March 10 and June 10, 2020.

Inclusion and exclusion criteria

At the time of the study, all pregnant women who gave birth at $\geq 36$ weeks were included. However, postpartum with a history of depression, chronic disease, multiple pregnancies, bad hemodynamics during the postpartum period, and mothers of infants with a low "Apgar Score" or those who needed resuscitation during the postpartum period were not included in the study.

\section{The sampling technique}

Considering the COVID-19 pandemic and the subsequent lockdown and social distancing, the patients were contacted personally through their registered phone at the hospital, and verbal consent was obtained from each patient willing to participate. The total number of pregnant women giving birth in this period was 1500; however, 1150 women met the study's inclusion criteria.

\section{Independent variable}

Education was categorized into low educated (under the high school) and high educated (above the high school). Employment is defined as either "employed or housewife". The monthly income of $4400 \mathrm{TL}$ is used as the cut-off point of low and high-income status. The exchange rate on 1st March 2020 was USD $1=$ TR 7.8. A family with two members is defined as a "nuclear family", and those exceeding two members are named "large families". The response to questions "having a history of psychiatric disease or a family member with a history of the psychiatric disease" was recorded into "Yes" or "No".

\section{Dependent variable}

The 7-item (5-point Likert scale) valid and reliable Turkish version of fcv-19s was recruited to collect the data [15]. The original version of fcv-19s was developed by Ahorsu et al. [16]. The total score was calculated by adding each item score (from 7 to 35). The higher the score, the greater the fear of COVID19.

\section{Data collection tools}

The survey includes an information form of 15 items regarding sociodemographic characteristics (age, educational background, and working status), pregnancy birth information (risky pregnancy status, the form of birth, and the week of birth), baby care, and nutrition information (breastfeeding, competence in care, and getting help) in three parts, and the questions of the Turkish version of the Fear of COVID-19 Scale (fcv-19s).

\section{Statistical analysis}

All statistical analyzes were performed using IBM SPSS version 22.0 (SPSS Inc., Chicago, Illinois, USA). Continuous variables are presented as Mean $\pm \mathrm{SD}$, and categorical variables are presented as numbers and percentages. Comparisons between groups were made using the Mann Whitney-U test for continuous variables. Spearman correlation analysis was used for the correlation relationship of continuous variables. Finally, linear regression analysis was performed to compare the Covid19 fear Scale and the related variables. A P-value of $<0.05$ was considered statistically significant.

\section{Results}

Characteristics of the participants

Out of 1150 eligible women, 906 were included in the study (response rate $60.4 \%$ ). The mean age was 29.59 ( \pm 4.74 years). Most of the respondents were high educated (75.2\%), housewives $(86.1 \%)$, nuclear family $(96.1 \%)$, and low-income ( $\leq 4400 \mathrm{TL}$ ) families $(53.9 \%)$. Most of the respondents neither having a history of psychiatric disease $(95.9 \%)$ nor having a family member with a history of psychiatric disease (87.3\%).

Table 1 Sociodemographic, personal, and genealogical characteristics of the participants

\begin{tabular}{ll}
\hline Variables & $\mathbf{N}(\%)$ \\
\hline Educational Background & \\
Lower than high school & $225(24.8)$ \\
High school and higher degree & $681(75.2)$ \\
Employment & \\
Employed & $126(13.9)$ \\
Housewife & $780(86.1)$ \\
Income Status & \\
Low ( $\leq 4400 \mathrm{TL})$ & $488(53.9)$ \\
High (>4400 TL) & $418(46.1)$ \\
Family Type & \\
Large family & $35(3.9)$ \\
Nuclear family & $871(96.1)$ \\
Having History of Psychiatric Disease & \\
No & $869(95.9)$ \\
Yes & $37(4.1)$ \\
Having a Family Member with History of & \\
Psychiatric Disease & \\
No & $791(87.3)$ \\
Yes & $115(12.7)$ \\
\hline
\end{tabular}

Pregnancy and birth information of the participants The details concerning the pregnancy and birth of the participants are provided in Table 2. The mean number of the participants' pregnancies was $1.89 \pm 1.03$; the mean number of follow-up during pregnancy was $11.11 \pm 2.96$. Most women made a planned $(96.1 \%)$ but not risky pregnancies $(82.7 \%)$, equal to or more than 38 weeks deliveries $(92.9 \%)$ by cesarean section $(\mathrm{C} / \mathrm{S})$ procedure $(71.7 \%)$.

Table 2 Pregnancy and birth information of the participants

\begin{tabular}{lll}
\hline Demographic variables & Categories & N (\%) \\
\hline Planned Pregnancy & No & $57(6.3)$ \\
& Yes & $849(96.1)$ \\
Risky Pregnancy & No & $749(82.7)$ \\
& Yes & $157(17.3)$ \\
Birth Week & $36-38$ & $64(7.1)$ \\
& $\geq 38$ & $842(92.9)$ \\
Form of Birth & NSD* & $256(28.3)$ \\
& $\mathrm{C} / \mathrm{S}^{*}$ & $650(71.7)$ \\
\hline
\end{tabular}

* NSD=Normal Spontaneous Delivery, $\mathrm{C} / \mathrm{S}=$ Cesarean Section

Postpartum baby care and breastfeeding status In Table 3, postpartum baby care and breastfeeding status were given. The majority of respondents were breastfeeding mothers (94.2\%). About seventy percent thought that milk is not 
enough; however, one-third $(34.3 \%)$ used feeding formula. Most women (91.2\%) felt components in baby care; however, $51.1 \%$ declared that they have an assistant for bay care. Most of the women (98.1\%) showed interest in the newborn monitoring and taking the infant to vaccination; however, few have doubts about the vaccine and fear catching an infection.

Table 3 Postpartum baby care and breastfeeding status

\begin{tabular}{lll}
\hline Demographic variables & Category & N $(\%)$ \\
\hline Feeling competent in baby care. & No & $80(8.8)$ \\
Having an assistant for baby care & Yes & $826(91.2)$ \\
& No & $262(28.9)$ \\
Breastfeeding status & Nes & $644(51.1)$ \\
& Yes & $53(5.8)$ \\
Thinking that milk is not enough & No & $253(94.2)$ \\
& Yes & $638(70.4)$ \\
Feeding formula & No & $595(65.7)$ \\
& Yes & $311(34.3)$ \\
Newborn monitoring/vaccination & No & $17(1.9)$ \\
status & & \\
Newborn monitoring/reasons for & Yes & $889(98.1)$ \\
not taking the infant to vaccination & & \\
Doubts about vaccine & & $5(30)$ \\
Fear of catching an infection & & $5(30)$ \\
Other & & $7(40)$ \\
\hline
\end{tabular}

The Spearman correlation test was performed to correlate between the fcv-19s survey score and the continuous dependent variables. A statistically significant correlation was found between the number of pregnancies $(\mathrm{Rho}=-0.183, \mathrm{p}<0.001)$ and the number of follow-ups $(\mathrm{Rho}=0.307, \mathrm{p}<0.001)$ with the total fcv-19s survey score. However, there was no statistically significant correlation between respondents' age and the total fcv-19s survey score $(\mathrm{rho}=-0.014, \mathrm{p}=0.664)$ (Table 4).

Relationship between fcv-19s survey score and the independent variables

The mean score of the fcv-19s scale was $(16.90 \pm 4.80$, range:730). In table 5, the Mann-Whitney U test was used to compare the mean between variables in the bivariate analysis. There was a statistically significant difference between the fcv-19s survey score and most of the independent variables. The high educated ( $\mathrm{P}<0.001)$, employed ( $\mathrm{P}=0.008)$, income 4400TL or less, nuclear family ( $\mathrm{P}=0.015)$, non-planned pregnancy $(\mathrm{P}=0.007)$, risky pregnancy $(\mathrm{P}=0.011)$, having a history of psychiatric disease $(\mathrm{P}<0.001)$, having a family member with a history of psychiatric disease $(\mathrm{P}<0.001)$, feeling not competent in baby care $(\mathrm{P}<0.001)$, underwent $\mathrm{C} / \mathrm{S}(\mathrm{P}<0.001)$, having an assistant for baby care $(\mathrm{P}=0.022)$, thinking that milk is not enough $(\mathrm{p}=0.028)$, feeding with a formula $(\mathrm{P}=0.006)$ and fear of COVID-19 ( $\mathrm{P}<0.001$ ) having higher fcv-19s survey score than their counterparts.
The linear regression analysis between FCV-19S survey score and the variables

The independent variables have significantly predicted the COVID-19 Fear Scale $(\mathrm{R}=0.67, \mathrm{R} 2=0.46, \mathrm{~F}=42.10, \mathrm{p}<$ $0.001)$ in the linear regression analysis. These significant variables describe approximately $46 \%$ of the total variance. Regression analysis showed that higher educated ( $\mathrm{P}$-value $=$ $0.022,<0.05)$, high income (P-value $=0.018,<0.05)$, increased number of follow up $(\mathrm{P}$-value $=\mathrm{p}<0.001,<0.05)$, having history of psychiatric disease $(\mathrm{P}$-value $=0.005,<0.05)$, positive family member with a history of psychiatric disease $(\mathrm{P}-\mathrm{value}=0.000$, $<0.05)$, gave birth by $\mathrm{C} / \mathrm{S}(\mathrm{P}$-value $=0.001,<0.05)$, incompetent in baby care $(\mathrm{P}$-value $=0.001,<0.05)$, breastfeeding $(\mathrm{P}-\mathrm{value}=$ $0.001,<0.05)$, adequate lactation $(\mathrm{P}$-value $=0.015,<0.05)$, feeding formula $(\mathrm{P}-\mathrm{value}=0.014,<0.05)$, and those who had a fear of COVID-19 (P-value $=\mathrm{p}<0.001,<0.05)$ were significantly associated with increased of the fcv-19s score.

\section{Discussion}

Pregnancy, childbirth, postpartum, and the adaptation period where mothers get used to their baby are the most sensitive times for women physically and spiritually. Therefore, there may be a risk of predisposition to psychological disorders. The negativity and uncertainty brought by the COVID-19 pandemic increased people's fear and anxiety [17]. Similarly, in our study, women who fear COVID-19 expressed the highest fcv-19s survey scores. The high scores of the fcv-19s survey in individuals with psychological disorders and a family member with psychological disorders may be due to these individuals' high susceptibility to psychological problems. Previous studies showed that many psychological disorders might have a genetic predisposition, and there is a high probability of recurrence $[18,19]$. In our study, the fcv-19s survey score was also high among the highly educated, good income, and employed mothers. These are interrelated socio-economic variables. Several studies have shown a positive correlation between the level of education and COVID-19 awareness [20-22]. Awareness can increase the fear of an outbreak that has not yet been cured and vaccinated. The negative economic impacts of the COVID-19 pandemic can also be the reason for increased fcv-19s survey scores in working individuals [23]. The low fcv19s survey scores among the individuals with planned and riskfree pregnancies may be related to the mothers' feeling emotionally healthy and ready. Previous studies showed a high rate of postpartum depression in mothers who do not have planned pregnancies or have risky pregnancies [24,25]. In our study, the reason behind the high fcv-19s survey scores among women who gave birth by $\mathrm{C} / \mathrm{S}$ may be explained by the fear of giving birth by surgery and longer hospitalization, which might result in being infected by the coronavirus.

Table 4 Correlation analysis results for the relationship between COVID-19 scale scores and some variables

\begin{tabular}{lccccc}
\hline Variables & & Age & Number of pregnancy & Number of those following & Measure of COVID-19 \\
\hline Age & $\mathrm{r}$ & 1 & & & \\
Number of pregnancy & $\mathrm{r}$ & $0.488^{* *}$ & 1 & 1 & \\
& $\mathrm{p}$ & $<0.001$ & & \\
Number of follow up & $\mathrm{r}$ & -0.026 & $-0.362^{* *}$ & $0.307^{* *}$ & 1 \\
& $\mathrm{p}$ & 0.443 & $<0.001$ & $<0.001$ & \\
The measure of COVID 19 & $\mathrm{r}$ & -0.014 & $-0.183^{* *}$ & $<0.001$ & \\
& $\mathrm{p}$ & 0.664 &
\end{tabular}

Table 5 Relationship between fcv-19s survey score and the independent variables $(n=906)$ 


\begin{tabular}{|c|c|c|c|c|}
\hline fcv-19s total Score & & $\mathrm{N}$ & Mean \pm SD & $P$-value \\
\hline \multirow[t]{2}{*}{ Educational Background } & Low educated & 225 & $15.07 \pm 4.72$ & $<0.001$ \\
\hline & High educated & 681 & $17.51 \pm 4.67$ & \\
\hline \multirow[t]{2}{*}{ Employment } & Employed & 126 & $17.97 \pm 4.26$ & 0.008 \\
\hline & Housewife & 780 & $16.73 \pm 4.85$ & \\
\hline \multirow[t]{2}{*}{ Income status } & Low $(\leq 4400 \mathrm{TL})$ & 488 & $16.44 \pm 4.60$ & 0.004 \\
\hline & High $(>4400$ TL) & 418 & $17.44 \pm 4.98$ & \\
\hline \multirow[t]{2}{*}{ Family type } & Large family & 35 & $15.00 \pm 4.68$ & 0.015 \\
\hline & Nuclear family & 871 & $16.98 \pm 4.79$ & \\
\hline \multirow[t]{2}{*}{ Planned pregnancy } & No & 57 & $18.72 \pm 4.49$ & 0.007 \\
\hline & Yes & 849 & $16.78 \pm 4.80$ & \\
\hline \multirow[t]{2}{*}{ Risky pregnancy } & No & 749 & $16.70 \pm 4.37$ & 0.011 \\
\hline & Yes & 157 & $17.85 \pm 5.01$ & \\
\hline \multirow[t]{2}{*}{ Having a history of psychiatric disease } & No & 869 & $16.70 \pm 4.69$ & $<0.001$ \\
\hline & Yes & 37 th & $21.65 \pm 4.92$ & \\
\hline \multirow[t]{2}{*}{ Having a family member with a history of psychiatric disease } & No & 791 & $16.33 \pm 4.63$ & $<0.001$ \\
\hline & Yes & 115 & $20.84 \pm 4.03$ & \\
\hline \multirow[t]{2}{*}{ Birth Week } & Preterm & 64 & $11.75 \pm 5.68$ & 0.296 \\
\hline & Term & 842 & $16.84 \pm 4.72$ & \\
\hline \multirow[t]{2}{*}{ Feeling competent in Baby Care. } & No & 80 & $20.56 \pm 4.13$ & $<0.001$ \\
\hline & Yes & 826 & $16.55 \pm 4.71$ & \\
\hline \multirow[t]{2}{*}{ Form of birth } & NSD & 256 & $13.80 \pm 4.27$ & $<0.001$ \\
\hline & $\mathrm{C} / \mathrm{S}$ & 650 & $18.12 \pm 4.40$ & \\
\hline \multirow[t]{2}{*}{ Having an assistant for baby care } & No & 262 & $16.35 \pm 5.07$ & 0.022 \\
\hline & Yes & 644 & $17.13 \pm 4.67$ & \\
\hline \multirow[t]{2}{*}{ Breastfeeding status } & No & 53 & $16.96 \pm 4.9$ & 0.082 \\
\hline & Yes & 853 & $16.02 \pm 1.81$ & \\
\hline \multirow[t]{2}{*}{ Thinking that milk is enough } & No & 268 & $17.49 \pm 4.72$ & 0.028 \\
\hline & Yes & 638 & $16.66 \pm 4.81$ & \\
\hline \multirow[t]{2}{*}{ Feeding with formula } & No & 595 & $16.56 \pm 4.86$ & 0.006 \\
\hline & Yes & 311 & $17.56 \pm 4.62$ & \\
\hline \multirow[t]{2}{*}{ Fear of COVID-19 } & No & 161 & $11.84 \pm 3.57$ & $<0.001$ \\
\hline & Yes & 745 & $18.00 \pm 4.30$ & \\
\hline \multirow[t]{2}{*}{ Newborn Monitoring/Vaccination status } & No & 17 th & $17.59 \pm 4.66$ & 0.493 \\
\hline & Yes & 889 & $16.89 \pm 4.80$ & \\
\hline
\end{tabular}

Table 6 Results of the linear regression analysis between fcv-19s survey score and the independent variables ( $\mathrm{n}=906$ )

\begin{tabular}{|c|c|c|c|c|c|c|}
\hline & $\mathrm{B}$ & SE & Beta & $\mathrm{t}$ & $P$-value & 95\% CL Lower-Upper \\
\hline Age & 0.008 & 0.031 & 0.008 & 0.260 & 0.795 & $-0.05,0.06$ \\
\hline (High educated (VS low educated) & 0.743 & 0.323 & 0.067 & 2.301 & 0.022 & $0.11,1.37$ \\
\hline Housewife (VS employed) & -0.053 & 0.365 & -0.004 & -0.144 & 0.886 & $-0.77,0.66$ \\
\hline High income (VS low income) & 0.618 & 0.261 & 0.064 & 2.371 & 0.018 & $0.10,1.13$ \\
\hline A large family (VS Nuclear family) & 0.821 & 0.643 & 0.033 & 1.276 & 0.202 & $-0.44,2.08$ \\
\hline Multipara (VS Primipara) & 0.168 & 0.152 & 0.036 & 1.104 & 0.270 & $-0.13,0.46$ \\
\hline Planned Pregnancy (VS not planned) & -0.915 & 0.554 & -0.046 & -1.652 & 0.099 & $-2.00,0.17$ \\
\hline Increased number of follow-up (VS No) & 0.230 & 0.047 & 0.142 & 4.932 & 0.000 & $0.13,0.32$ \\
\hline Risky Pregnancy (VS No) & -0.328 & 0.345 & -0.026 & -0.953 & 0.341 & $-1.00,0.34$ \\
\hline Having History of Psychiatric Disease (VS No) & 1.822 & 0.648 & 0.075 & 2.810 & 0.005 & $0.55,3.09$ \\
\hline History of psychiatric disease in the family (VS No) & 2.577 & 0.410 & 0.179 & 6.289 & 0.000 & $1.77,3.38$ \\
\hline C/S (VS NSD) & 2.434 & 0.308 & 0.228 & 7.902 & 0.000 & $1.82,3.03$ \\
\hline Feeling Incompetent in Baby Care (VS Competent) & -2.078 & 0.450 & -0.123 & -4.624 & 0.000 & $-2.96,-1.19$ \\
\hline Having an Assistant for Baby Care (VS No) & -0.153 & 0.274 & -0.014 & -0.557 & 0.578 & $-0.69,0.38$ \\
\hline Breastfeeding (VS No) & 1.994 & 0.576 & 0.097 & 3.459 & 0.001 & $0.86,3.12$ \\
\hline Thinking that Milk is Enough (VS No) & 1.395 & 0.571 & 0.133 & 2.441 & 0.015 & $0.27,2.51$ \\
\hline Feeding Formula (VS No) & 1.409 & 0.575 & 0.139 & 2.452 & 0.014 & $0.28,2.53$ \\
\hline
\end{tabular}

A decrease in the fcv-19s survey scores was determined as the number of pregnancies increased in our study. The reason may relate to mother's previous knowledge and experience. Lack of knowledge and inexperience among mothers cause a feeling of 
incompetence to care for the baby [26]. Moreover, the present study showed that women who feel inadequate in baby care had high fcv-19s survey scores.

In $2005,74.2 \%$ of US infants were breastfed at least once after delivery, but only $31.5 \%$ were exclusively breastfed at the age of 3 months [27]. According to Turkey's Population and Health Research 2013 data, only $57.9 \%$ of babies were breastfed in the first two months of life [28]. In our study, the continuation rate of breastfeeding was $94.6 \%$. However, the rate of the "only-breastfed infants" accounted for $65.5 \%$. We think that the high proportions are due to the characteristics of the surveyed sample. Peregrin $T$ [29] emphasized that the main cause of inadequate breastfeeding is a lack of knowledge about breastfeeding. Furthermore, Swanson and Kevin [30] indicated that nursing and family support are also important and training programs for breastfeeding education and support. Likewise, the less fear among mothers living in a large family in our study may be due to the fact that they received support from other family members during the postpartum period. At this point, we believe that displaying videos about COVID-19, breastfeeding and baby care, and useful practices to mothers during hospitalization before or after childbirth will significantly reduce the fear of COVID-19 and positively inform the mother regarding breastfeeding and baby care. Although there was no significant correlation, the fcv-19s survey scores were higher among non-breastfeeding mothers than their counterparts. However, the regression analysis correlation with other factors indicates that the fcv-19s survey score can disrupt breastfeeding when combined with other risk factors. For example, in the postpartum period, it is necessary to take a holistic evaluation. Otherwise, postpartum negative effects may disrupt breastfeeding [31]. Additionally, anxiety, stress, and fear sometimes make breastfeeding inefficient and can often lead to its interruption [32,33]. We know that breastfeeding is more than a choice and is the most important investment in the future for both mother and baby [34]. It is believed that, beyond its benefits and health investments that are not limited to the actual breastfeeding period, it has long-term effects on long-term quality of life and strengthens the immune system [35]. The WHO recommends extending this precious process up to 2 years, not only six months [36,37]. Supporting breastfeeding, which is important for generations, is important for individual and community health [38]. Our study's limitations are the inability to evaluate observational symptoms due to the survey via phone call. Organizing prenatal and postnatal training to reduce the fear of COVID-19 will positively affect both the psychological state of the mother and breastfeeding. Besides, individuals who are at risk of high fear, especially those who have a history of psychological disorders and a family member with a history of psychological disorders, should be intervened through online support programs, if necessary. Our study's clinical results are of significance since they identify the issues that should be considered to provide nursing support to mothers during this process and establish strategies for reducing breastfeeding discontinuation during the COVID-19 pandemic period.

\section{Conclusion}

It is concluded that during the COVID-19 pandemic, COVID19 fear and related factors combined affect breastfeeding among mothers. We believe that mothers' holistic evaluation in this period and conducting awareness-raising works are necessary to reduce the psychological burden created by the COVID-19 pandemic. Integrating the issues related to the COVID-19 pandemic into educational materials used in pregnancy, childbirth, and the postpartum period will yield an increased level of knowledge about corvid-19. This will positively affect the relationship between mother and baby as well as breastfeeding, which will reduce anxiety and postpartum psychological load.

\section{Abbreviation}

COVID-19: Coronavirus Disease-19; WHO :World Health Organization; fcv-19s :Fear of COVID-19 Scale; NSD: Normal Spontaneous Delivery; C/S: Cesarean Section

\section{Declaration}

Acknowledgment

We would like to thank Mrs. Melisa Naz for his great efforts in helping to prepare the questionnaires and the necessary links and distribution through the social networking sites. We also extend our thanks to all respondent to the survey during the Coronavirus pandemic.

\section{Funding}

The author received no financial support for the research, authorship, and/or publication of this article.

\section{Availability of data and materials}

Data will be available by emailing asiye.uzun@ nisahastanesi.com

\section{Authors' contributions}

Authors are equally participated in the concept, design, writing, reviewing, editing, and approving the manuscript in its final form. All authors have read and approved the final manuscript.

\section{Ethics approval and consent to participate}

We conducted the research following the Declaration of Helsinki, and the protocol was approved by the Non-Interventional Ethics Committee of Medipol University Faculty of Medicine, Istanbul, Turkey by Decision Number 31 on 07/23/2020.

\section{Consent for publication}

Not applicable

\section{Competing interest}

The authors declare that they have no competing interests.

\section{Open Access}

This article is distributed under the terms of the Creative Commons $\begin{array}{llll}\text { Attribution } & 4.0 & \text { International License }\end{array}$ (http://creativecommons.org/licenses/by/4.0/), which permits unrestricted use, distribution, and reproduction in any medium, provided you give appropriate credit to the original author(s) and the source, provide a link to the Creative Commons license, and indicate if changes were made. The Creative Commons Public Domain Dedication waiver (http://creativecommons.org/publicdomain/zero/1.0/) applies to the data made available in this article, unless otherwise stated. Author details 
${ }^{1}$ Department of Obstetrics and Gynecology, Medipol Teaching and Research Hospital, Istanbul, Turkey. ${ }^{2}$ Department of Family Medicine Şişli Etfal Training and Research Hospital İstanbul, Turkey.

Article Info

Received: 07 January 2021

Accepted: 03 February 202

Published: 22 March 2021

\section{References}

1. World Health Organization, Coronavirus disease 2019 Situation Report. Available from: https://www.who.int/docs/defaultsource/coronaviruse/situation-reports/20200312-sitrep52-covid19.pdf?sfvrsn=e2bfc9c0_4 [Access on 10 May 2020].

2. T.C. Department of Health, COVID-19 [(SARS-CoV-2 Infection] Guide. Available from: https://covid19bilgi.saglik.gov.tr/depo/rehberler/COVID19_Rehberi.pdf [Access on 02 May 2020].

3. Dr. Fahrettin Koca. Disclosures of the Minister of Health Available from: http://twitter.com/drfahrettinkoca

4. Ali Jadoo SA. Was the world ready to face a crisis like COVID19? Journal of Ideas in Health2020;3(1):123-4 https://doi.org/10.47108/jidhealth.Vol3.Iss1.45

5. Lin CY. Social reaction toward the 2019 novel coronavirus. Social Health and 3(1):1-2. https://doi.org/:10.4103/SHB.SHB_11_20.

6. Collin J, Byström E, Carnahan A, Ahrne M. Public Health Agency of Sweden's Brief Report: pregnant and postpartum women with severe acute respiratory syndrome coronavirus two infection in intensive care in Sweden. Acta ObstetGynecolScand2020; 99(7): 819-822. https://doi.org/10.1111/aogs.13901

7. Zeng L, Xia S, Yuan W, Yan K, Xiao F, Shao J. Neonatal earlyonset infection with SARS-CoV-2 in 33 neonates born to mothers with COVID-19 in Wuhan, China. JAMA Pediatrics 2020; 174 (7): 722-725 HTTP:// doi.org 10.1001 / jamapediatrics.2020.0878.

8. Chen H, Guo J, Wang C, Luo F, Yu X, Zhang W, et al. Clinical characteristics and intrauterine vertical transmission potential of COVID-19 infection in nine pregnant women: a retrospective review of medical records. The Lancet 2020;395(10226):809-815. https://doi.org/10.1016/S0140-6736(20)30360-3.

9. Zhu H, Wang L, Fang C, Peng S, Zhang L, Chang G, et al. Clinical analysis of 10 neonates born to mothers with 2019-nCoV pneumonia. Transl Pediatrics2020;9(1):51 -60. https://doi.org $/ 10.21037$ / tp.2020.02.06

10. Qiao J. What are the risks of COVID-19 infection in pregnant women? The Lancet. 2020; 395(10226):760 -762 . https://doi.org/10.1016/S0140-6736(20)30365-2

11. Asadi L, Tabatabaei R S, Safinejad H, Mohammadi M. New Corona Virus (COVID-19) Management in Pregnancy and Childbirth, Arch Clin Infect Dis. Online ahead of Print ; 15(COVID-19):e102938. https://doi.org /10.5812/archcid.102938.

12. World Health Organization. Coronavirus disease outbreak 2020. Available from: https://www.who.int/emergencies/diseases/ novelcoronavirus-2019 [Access on 15 April 202015.04.2020]

13. Hayes AF. Introduction to mediation, moderation, and conditional process analysis: a regression-based approach. New York Guilford Publications 2018

14. O'Brien M, Buikstra E, Hegney D. The influence of psychological factors on breastfeeding duration. J Adv Nurs 2008; 63(8):397 408. https://doi.org/10.1111/j.1365-2648.2008.04722.x
15. Haktanir A, Seki T, Dilmaç B. Adaptation and evaluation of Turkish version of the fear of COVID-19 Scale. Death Stud. 2020 May 29:1-9. https://doi.org/10.1080/07481187.2020.1773026.

16. Ahorsu DK, Lin CY, Imani V, Saffari M, Griffiths MD, Pakpour AH. The Fear of COVID-19 Scale: Development and Initial Validation. Int J Ment Health Addict. 2020 Mar 27:1-9. https://doi.org/10.1007/s11469- 020-00270-8.

17. Mertens G, Gerritsen L, Duijndam S, Salemink E, Engelhard IM Fear of the coronavirus (COVID-19): predictors in an online study conducted in March 2020. J Anxiety Disord. 2020 Aug; 74:102258. https://doi.org/10.1016/j.janxdis.2020.102258

18. Badner JA, Gershon ES. Meta-analysis of whole-genome linkage scans of bipolar disorder and schizophrenia Mol Psychiatry. 2002;7:405-411. https://doi.org/:10.1038/sj.mp.4001012),]

19. Nager A, Szulkin, R, Johansson SE, Johansson LM , Sundquist, K. High lifelong relapse rate of psychiatric disorders among women with postpartum psychosis. Nordic Journal of Psychiatry 2012;67(1):

$53-58$ https://doi.org/10.3109/08039488.2012.675590

20. Zhong, BL, Lui W, Li MH ,Zhang QQ, Liu GX, Li W, et al. Take meat. "Knowledge, attitudes, and practices towards COVID-19 among Chinese residents during the rapid rise period of the COVID-19 outbreak: a quick online cross-sectional survey." International journal of biological sciences 2020; 16 (10): 1745-175. https://doi.org/ 10.7150 / ijbs.45221

21. Ali Jadoo SA, Alhusseiny A, Yaseen S, Al-Samarrai M, Al-Rawi R, Al-Delaimy A, Abed M, Hassooni H. Knowledge, attitude, and practice toward COVID-19 among Iraqi people: a web-based cross-sectional study. Journal of Ideas in Health 2020;3(Special2):258-65.

https://doi.org/10.47108/jidhealth.Vol3.IssSpecial\%202.59

22. Ali Jadoo SA, Dastan I, Al-Samarrai M, Yaseen S, Abbasi A, Alkhdar H, Al Saad M, Danfour O. Knowledge, attitude, and practice towards COVID-19 among Syrian people resident in Turkey. Journal of Ideas in Health 2020;3(Special2);3(Special2):278-85.

https://doi.org/10.47108/jidhealth.Vol3.IssSpecial2.61

23. Baldwin R, Weder di Mauro B. Economics in the Time of COVID-19. A CEPR Press VoxEU.org eBook. Available from: https://voxeu.org/content/economics-time-covid-19 [Access on 06 March 2020]

24. Faisal-Cury A, Menezes PR, Quayle J, Matijasevich A Unplanned pregnancy and risk of maternal depression: secondary data analysis from a prospective pregnancy cohort. Psychology, Health and Medicine 2017;22(1): 65-74 https://doi.org/10.1080/13548506.2016.1153678.

25. Durukan E, Ilhan MN, Bumin MA, Aycan S. Prevalence of postpartum depression and quality of life in mothers with 2 weeks-18 months baby. Balkan Medical Journal 2011;28(4): 385393. https://doi.org/10.5174/tutfd.2010.04117.3.

26. Çalık KY, Çetin FC, Erkaya R. Applications of mothers in breastfeeding and affecting factors. Gümüşhane University Journal of Health Sciences 2017; 6(3): 80-91.

27. Centers for Disease Control and Prevention Breastfeeding Among U.S. Children Born 1999-2005, CDC National Immunization Survey. Atlanta, GA: Centers for Disease Control and Prevention. Available

from: http://www.cdc.gov/breastfeeding/data/NIS_data/index.htm. [Accessed on 10 June 2020] 
28. TNSA 2013 Results - Turkish Population and Health Research TNSA2013 - Population Studies. Available from: http://www.hips.hacettepe.edu.tr/tnsa2013/rapor/tnsa2 013_sonuclar_sunum_21222014.pdf [Accessed on 02 May 2020].

29. Peregrin T. Education, peer counselling and parental support. Three ways to encourage a healthful breastfeeding schedule. Journal of American Dietetic Association 2002:102(7): 943. https://doi.org/10.1016/S0002-8223(02)90215-4

30. Swanson V, Kevin G. Initiation and continuation of breastfeeding: theory of planned behavior. Journal of Advanced Nursing 2005;50(3): 272-282. https://doi.org/10.1111/j.13652648.2005.03390.x

31. Davanzo R, Moro G, Sandri F, Agosti M, Moretti C, Mosca F. Breastfeeding and coronavirus disease-2019: Ad interim indications of the Italian Society of Neonatology endorsed by the Union of European Neonatal \& Perinatal Societies. Matern Child Nutr. 2020 Jul;16(3):e13010. https://doi.org/10.1111/mcn.13010.

32. Ystrom E, Niegel S, Klepp KI, Vollrath ME. The impact of maternal negative affectivity and general self-efficacy on breastfeeding: The Norwegian Mother and Child Cohort Study. J. Pediatric 2008; 152: 68-72. https://doi.org/: 10.1016/j.jpeds.2007.06.005
33. Mezzacappa ES, Katkin ES. Breastfeeding is associated with reduced perceived stress and negative mood in mothers. Health Psychol2002;21(2):187-193. https://doi.org/10.1037/02786133.21.2.187

34. Rollins NC, Bhandari N, Hajeebhoy N, et al. Why invest, and what it will take to improve breastfeeding practices? Lancet (London, England). $2016 \quad J a n ; 387(10017): 491-504$. https://doi.org/10.1016/s0140-6736(15)01044-2.

35. Turck D, Vidailhet M, Bocquet A, Bresson JL,Briend A, et al.Comité de nutrition de la Société française de pédiatrie. Breastfeeding: health benefits for child and mother Arch Pediatrics 2013;20(2): 29-48. https://doi.org/:10.1016/S0929693X (13) 72251-6

36. World Health Organization, Health Topics. Breastfeeding. Available from: https://www.who.int/topics/breastfeeding/en [Accessed on 12 Jan 2019].

37. Smith HA, Becker GE. Early additional food and fluids for healthy breastfed full-term infants. Cochrane Database Syst Rev. 2016;

8:CD006462 https://doi.org/10.1002/14651858.CD006462.pub4

38. 3Spiro A. The public health benefits of breastfeeding. Perspect Public Health. 2017;137 (06) :307-308. https://doi.org/:10.1177/1757913917734139 